\title{
PROPOSTA DE INDICADORES PARA SISTEMA DE INTELIGÊNCIA COMPETITIVA EM INSTITUIÇÃO DE ENSINO SUPERIOR
}

\section{A PROPOSAL FOR THE USE OF INDICATORS IN A COMPETITIVE INTELLIGENCE SYSTEM FOR AN INSTITUTION OF HIGHER EDUCATION}

\author{
Caio Márcio Gonçalves \\ Mestre em Engenharia de Produção pela UFSC \\ Professor da Universidade de Uberaba- MG - UNIUBE \\ End.: Rua Egídio Botta, 399 - Bairro Olinda \\ Uberaba - Minas Gerais - CEP 38045-550 \\ Tel. (34) 33365753 -E-mail: caio.gonçalves@uniube.br
}

\author{
Romualdo Douglas Colauto \\ Doutor em Engenharia de Produção pela UFSC \\ Professor do Programa de Mestrado em Ciências Contábeis da Universidade \\ Federal de Minas Gerais - FACE/UFMG
}

End. Rua Curitiba, 832 sala 709 - Centro - Belo Horizonte - MG - Brasil - CEP 88101-440

Tel. (31) 32799056 - E-mail: rdcolauto@face.ufmg.br

\section{Ilse Maria Beuren}

Doutora em Controladoria e Contabilidade FEA/USP

Professora do Programa de Pós-Graduação em Ciências Contábeis da Universidade Regional de Blumenau (PPGCC - FURB) - Santa Catarina

Endereço: Rua Antonio da Veiga, 140 - Victor Konder - Blumenau - Santa Catarina - Brasil

CEP 89010-500 - Tel. (47) 3210565 -E-mail: ilse@furb.br

\begin{abstract}
Resumo
A inteligência competitiva está vinculada à administração, utilização e disseminação da informação para atingir os objetivos estratégicos e táticos da organização. O artigo objetiva apresentar uma proposta de indicadores para um sistema de inteligência competitiva em instituição de ensino superior. Realizou-se uma pesquisa exploratória, com abordagem predominantemente qualitativa, por meio de um estudo de caso centrado em uma instituição de ensino superior. Na coleta de dados optou-se pela técnica de entrevista semi-estruturada aplicada à Pró-reitora de Ensino da instituição para identificar a infra-estrutura existente e as atividades institucionais objeto de pesquisa. Para interpretação dos dados, utilizou-se da análise de conteúdo. O estudo resulta em um conjunto de indicadores para monitoramento dos clientes, concorrentes, fornecedores e órgãos reguladores segmentados nos níveis estratégico, pedagógico e administrativo, os quais podem ser utilizados para acompanhar ações planejadas e executadas ao longo do tempo. A pesquisa representa sugestões iniciais para que cada instituição possa criar seus próprios indicadores, de acordo com suas necessidades informacionais e realidade local.
\end{abstract}

Palavras-chave: Inteligência competitiva. Indicadores. Instituição de ensino superior. 


\begin{abstract}
Competitive Intelligence is linked to the administration, utilization and dissemination of information to reach an organization's strategic and tactical objectives. The aim of this study is to propose the use of indicators for a competitive intelligence system in an institution of higher education. For this, exploratory research was carried out using a predominantly qualitative approach, through a case study centered on an institution of higher education. Data was collected through the application of semi-structured interviews of the teaching prorectory of the institution to identify the existent infrastructure and the institutional activities pertinent to this research. To interpret the data collected, content analysis was used. The study produced a set of indicators for monitoring clients, competitors, suppliers, and regulatory bodies segmented into strategic, pedagogical and administrative levels, which can be used to follow plans and actions over time. The research makes preliminary suggestions for each institution to be able to create its own indicators, in accordance with its information needs and the local conditions which apply.
\end{abstract}

Keywords: Competitive intelligence. Indicators. Higher education institution.

\title{
1 Introdução
}

As mudanças e as conseqüentes ameaças e oportunidades criam continuamente sinais e mensagens no ambiente de negócios. As organizações detectam essas mensagens, executam algum tipo de processamento para transformá-las em informação e as utilizam para se adaptarem às condições do mercado. Quando as decisões se baseiam nessas mensagens, novas informações são produzidas e transmitidas, gerando novos sinais. As organizações dependem do inter-relacionamento em seus ambientes e a sobrevivência pode ser parcialmente obtida pela habilidade de enfrentar as contingências ambientais (MORESI, 2001).

De acordo com Choo (1998) grande parte das mudanças no ambiente externo cria sinais e mensagens para os quais as organizações devem atentar. Alguns desses sinais são facilmente identificáveis, outros confusos ou espúrios. Assim, na coleta de dados, a organização deve observar, seletivamente, a qualidade dos sinais criados pela dinamicidade do ambiente no qual está inserida, interpretar as mensagens confusas e tentar perceber se há indícios relevantes à execução dos objetivos institucionais.

O conhecimento é interpretado como um dos fatores críticos, que contribui para a antecipação de mudanças. Isto conduz ao desenvolvimento da aprendizagem organizacional, gestão do conhecimento e à inteligência competitiva (IC), como áreas de interesse estritamente ligadas às mudanças na concepção da gestão. A interconexão dessas áreas representa a capacidade efetiva, tanto de adquirir como de operacionalizar conhecimento para lidar com mudanças (NONAKA e TAKEUCHI, 1997; BAÊTA, MARTINS e BAÊTA, 2002). 
Davenport (1998) expõe que um enfoque importante para as organizações é o conceito da engenharia de informação, compreendida como a construção e manutenção de modelos detalhados de uso e relações de elementos de dados em toda a empresa. A engenharia da informação é uma abordagem para separar as aplicações e os dados, evitando armazenamento de informações redundantes, isto implica que as exigências dos dados sejam exaustivamente definidas. O objetivo circunscreve-se em torno da criação de um banco de dados, bem estruturado, para áreas de assuntos considerados importantes e diretamente relacionados com os clientes, produtos, infra-estrutura, para subsidiar o processo decisório da organização.

Todavia, os tomadores de decisões nas organizações trabalham com grande quantidade de dados em estado bruto e quantidade reduzida de informação com valor agregado e, como conseqüência, pouca inteligência para subsidiar o processo decisório. O sistema de inteligência competitiva pode ser compreendido como resultado da análise de dados e informações coletados do ambiente competitivo da empresa, servindo de base para tomada de decisão. Tem ainda como objetivo gerar recomendações que consideram eventos futuros e não somente relatórios para justificar decisões pretéritas (GOMES e BRAGA, 2001).

No que concerne às instituições de ensino superior, particularmente universidades privadas, assume-se que o setor de prestação de serviços na área da educação deve ser entendido como uma atividade empresarial semelhante a outros ramos de negócio. A universidade está, portanto, sujeita às crescentes pressões competitivas que afligem a todos os mercados, independente da forma ou da área de atuação das empresas que os compõem.

Segundo Ayres et al. (1999), a inserção da universidade, antes norteada apenas pelo enfoque acadêmico, em um modelo de gestão empresarial é premente para a diferenciação destas instituições no mercado. A concepção de uma matriz de indicadores para visualizar o processo de gestão universitária nos níveis estratégico, pedagógico e administrativo possibilita visualizar os principais focos de atuação destas instituições e, concomitantemente, redirecionar estratégias competitivas. Nessa perspectiva, o artigo tem por objetivo propor indicadores para dar suporte a um sistema de inteligência competitiva em instituição de ensino superior.

Quanto à organização do conteúdo, inicialmente são demonstrados os procedimentos metodológicos que nortearam o desenvolvimento da pesquisa. $\mathrm{Na}$ seqüência faz-se uma incursão nas abordagens e aspectos conceituais de inteligência competitiva. Em seguida, caracteriza-se instituição de ensino superior e propõe-se uma matriz de indicadores para monitorar um sistema de inteligência competitiva para estas instituições. Após, descreve-se como a proposta pode ser operacionalizada na instituição de ensino superior pesquisada. Por Revista Produção Online, Florianópolis, v.7, n.7,p.41, dez./abr., 2007 
fim, apresentam-se os fatores facilitadores e restritivos para implementação da proposta, além das considerações finais do estudo.

\section{Procedimentos metodológicos}

O delineamento da pesquisa caracteriza-se como estudo exploratório, utilizando-se de fontes secundárias, com abordagem lógica dedutiva. De acordo com Tripodi, Fellin e Meyer (1981, p.64), o estudo exploratório tem por finalidade principal "desenvolver, esclarecer e modificar conceitos e idéias, a fim de fornecer hipóteses pesquisáveis para estudos posteriores". Ao se referir à pesquisa exploratória, Andrade (2002) elenca como finalidades substanciais: a) proporcionar maiores informações sobre o assunto que se vai investigar; b) facilitar a delimitação do tema de pesquisa; c) orientar a fixação dos objetivos e a formulação das hipóteses; e, d) descobrir um novo tipo de enfoque sobre o assunto.

A abordagem lógica dedutiva, segundo Popper (1972, p.33), é um método para submeter uma idéia nova, formulada conjecturalmente e ainda não justificada de algum modo (antecipação, hipótese, sistema teórico ou algo análoga), a partir da qual se pode tirar conclusões por meio de dedução lógica. De acordo com o autor supracitado, essas conclusões são em seguida comparadas entre si e com outros enunciados pertinentes, de modo a descobrir-se que relações lógicas (equivalência, dedutibilidade, comparabilidade ou incomparabilidade) existem no caso.

A pesquisa bibliográfica, de acordo com Cervo e Bervian (1983), busca explicar um problema a partir de referenciais teóricos já publicados. Pode ser utilizada independentemente ou como parte de uma pesquisa descritiva ou experimental. Tem por finalidade conhecer e analisar as contribuições culturais ou científicas do passado acerca de um determinado assunto ou problema. Para Marconi e Lakatos (2002), abrange a bibliografia já tornada pública em relação ao tema de estudo. Sua finalidade é colocar o pesquisador em contato direto com os estudos já realizados.

Dessa forma, utilizou-se a pesquisa bibliográfica para a formação do marco referencial teórico e do estudo de caso centrado em uma única organização. O estudo de caso, de acordo com Raupp e Beuren (2003), predomina nas pesquisas em que se desejam aprofundar conhecimentos a respeito de uma situação específica. Salientam que o pesquisador tem a oportunidade de verificar in loco os fenômenos a serem pesquisados.

A escolha do sujeito da pesquisa para analisar a possibilidade de operacionalização da proposta de matriz de indicadores para monitoramento do sistema de inteligência competitiva foi intencional em função da acessibilidade aos dados. Trata-se de uma instituição de ensino Revista Produção Online, Florianópolis, v.7, n.7,p.42, dez./abr., 2007 
superior privada, localizada na cidade de Uberaba-MG. Quanto aos procedimentos de coleta de dados, optou-se pela entrevista semi-estruturada com a Pró-reitora de ensino da instituição, realizada em janeiro de 2005, para identificar os recursos relacionados à infra-estrutura necessária para operacionalizar os indicadores para o sistema de inteligência competitiva. A escolha do respondente deu-se em função de sua visão sistêmica e do conhecimento dos diversos níveis da gestão universitária. E ainda, devido a sua participação em comitês de planejamento e relacionamento com a entidade mantenedora da Instituição.

Para a análise e interpretação dos dados utilizou-se da técnica de análise de conteúdo, que possibilita compreender melhor o discurso, aprofundar suas características e extrair os momentos mais importantes, por meio de procedimentos sistemáticos e objetivos de descrição dos conteúdos das mensagens. Bardin (1977 apud TRIVIÑOS, 1987) explica que a técnica de conteúdo pode ser entendida como um conjunto de técnicas de análise das comunicações que visa, por meio de procedimentos sistemáticos e objetivos, descrever o conteúdo das mensagens, obter indicadores quantitativos, ou não, que permitam a inferência de conhecimentos relativos às condições de produção/recepção de variáveis das mensagens.

Em relação aos procedimentos sistemáticos para a descrição e explicação dos fenômenos, o estudo se desenvolve num ambiente que preconiza a abordagem qualitativa. $\mathrm{O}$ método qualitativo, conforme Richardson (1999), caracteriza-se pelo não emprego de instrumental estatístico como base no processo de análise de um problema. Isto é, não se atém a numerar ou medir unidades ou categorias homogêneas.

\section{Aspectos conceituais de inteligência competitiva}

Tyson (1998) considera inteligência competitiva como um processo sistemático, que transforma bits e partes de informações competitivas em conhecimento estratégico para a tomada de decisão. Este conhecimento é referente à posição competitiva atual, desempenho, pontos fortes e fracos, e intenções específicas para o futuro. Rostaing et al. (1993 apud POZZEBON et al., 1997) definem IC como conjunto das atividades de controle do ambiente de uma empresa, visando fornecer dados úteis à definição de suas estratégias de evolução.

A inteligência competitiva pode ser entendida como o conjunto de processos e ferramentas para selecionar, analisar, comunicar e gerenciar as informações externas à empresa. Tem como objetivo principal obter informações para decisões, apoiar projetos, auxiliar em treinamentos e o aprendizado contínuo por meio do monitoramento do ambiente competitivo (TEIXEIRA FILHO, 2000). 
A inteligência competitiva é um conjunto de métodos e técnicas utilizados no tratamento da informação para tomada de decisão. É vista como uma metodologia que permite o monitoramento informacional da ambiência e, quando sistematizado e analisado, gera informações estratégicas para dar suporte aos gestores (TARAPANOFF, 2001).

Ueno (2001) apresenta diferentes conceitos de inteligência competitiva, partindo da visão de Fuld (1995), Hering (1997) e Kahaner (1998). Menciona que Fuld (1995) conceitua a inteligência competitiva como as informações analisadas sobre os concorrentes que tem implicações no processo de tomada de decisão. Para Hering (1997), é um processo organizacional de coleta e análise sistemática de informação, que por sua vez é disseminada como recurso para apoiar a tomada de decisão. Kahaner (1998) mostra a IC como um programa sistemático de coleta e análise da informação sobre as atividades dos concorrentes e tendências gerais dos negócios, visando atingir as metas da empresa.

$\mathrm{O}$ processo de inteligência competitiva permite à organização identificar ameaças competitivas, eliminar ou reduzir surpresas, reduzir o tempo de reação, identificar oportunidades latentes. E ainda, gerenciar clientes, antecipar necessidades e desejos dos consumidores, monitorar as estratégias dos concorrentes, difundir as informações na organização, preservar a vantagem competitiva e monitorar tecnologias em desenvolvimento.

A organização pode assegurar maior competitividade ao identificar eventos considerados pouco relevantes, transformando-os em oportunidades. A concorrência, o cliente e demais interlocutores do processo organizacional emitem sinais fracos, que eventualmente podem não ser percebidos pelos gestores, requerendo o monitoramento contínuo do macro e micro ambientes (COLAUTO et at., 2004). Por conseguinte, a decodificação destes sinais demanda um sistema de IC, capaz de auxiliar efetivamente no processo de tomada de decisão.

A abordagem de inteligência competitiva volta-se à busca de contribuições dos conteúdos em gestão de projetos, de informação, tecnológica e de pessoas. Em princípio, o sistema de inteligência competitiva deve proporcionar meios para que a informação chegue em tempo, forma adequada e para a pessoa certa.

Em um sistema de inteligência competitiva, todas as informações coletadas são consideradas inteligência bruta, ou seja, necessitam ser trabalhadas para apresentar um valor maior. Além disso, é necessário compreender as pessoas como fatores críticos de sucesso do sistema de inteligência competitiva, uma vez que profissionais de inteligência competitiva são necessários em alguns pontos do sistema, seja na identificação das necessidades do usuário, na coleta da informação, criação e distribuição dos produtos de inteligência competitiva e na proteção à apropriação indébita (GOMES e BRAGA, 2001).

Revista Produção Online, Florianópolis, v.7, n.7,p.44, dez./abr., 2007 
Segundo Laudon e Laudon (2001), as tecnologias de informação e a implantação de sistemas de informação apóiam a inteligência competitiva e devem ocorrer mediante uma abordagem sistêmica. Isto requer considerar a organização como um sistema sociotécnico aberto e recusar o determinismo tecnológico. Muito embora o sistema possa ser bem sucedido tecnicamente, pode falhar do ponto de vista organizacional devido à deficiência nos processos sociais e políticos de construção do mesmo. Ressaltam a importância da participação e comprometimento dos membros-chave da organização para conferir maior probabilidade de sucesso na implantação de inovação tecnológica.

Os sistemas de informação de suporte ao sistema de inteligência competitiva precisam apresentar natureza sociotécnica. Muito embora o processo de inteligência competitiva apresente robustez tecnológica, somente o homem, através de sua capacidade de raciocínio, pode avaliar as informações e adicionar valor à sua formatação final.

A abordagem sociotécnica recomenda que o indivíduo deve ser o elemento-base sobre o qual o trabalho precisa ser organizado. O paradigma sócio-técnico é confirmado por meio do conceito de Ecologia da Informação, proposto inicialmente por Davenport (1998). O conceito de ecologia da informação fundamenta-se na administração informacional centrada no ser humano. Na teoria da ecologia da informação, a informação e o conhecimento são próprios da criação humana, e administrá-los, adequadamente, requer considerar que as pessoas têm um papel fundamental neste cenário.

Os sistemas de informação, na ótica da abordagem sociotécnica, são considerados um arranjo de elementos técnicos e sociais. A implantação de um sistema de informação transcende ao determinismo tecnológico, pois seu reflexo percorre toda organização, inclusive provocando mudanças nos cargos, nas habilidades, no gerenciamento, isto é, modifica o arranjo e a forma do trabalho organizacional (LAUDON e LAUDON, 2001).

Com relação às etapas do sistema de inteligência competitiva, de acordo com Santos (1999), dividem-se em: a) identificação das necessidades de informação; b) coleta das informações; c) análise das informações; d) disseminação; e, e) avaliação. Quanto à atividade de análise das informações o sistema de inteligência competitiva requer que se faça, previamente, a organização, classificação, indexação e resumo destas. Para isso, pode-se utilizar uma matriz de indicadores que permite classificar e melhor visualizar um conjunto de informações que serão periodicamente monitoradas e retroalimentarão o sistema de inteligência competitiva como suporte ao processo decisório.

Os indicadores da matriz de inteligência competitiva, quando aplicados em instituições de ensino superior devem se ater a monitorar as ações empregadas nos vários níveis da gestão Revista Produção Online, Florianópolis, v.7, n.7,p.45, dez./abr., 2007 
acadêmica. Em princípio, indicadores são medidas de desempenho de ações desenvolvidas na instituição. Tratam-se de informações qualitativas e quantitativas, que por meio de seu registro e acompanhamento mostram o desempenho ou comportamento de atividades, funções, requisitos ou até mesmo da instituição em sua totalidade. Os indicadores apresentam abrangência estratégica, tática e operacional (REZENDE e ABREU, 2000). Para efeito deste estudo, a abrangência tática é entendida como nível pedagógico, a abrangência operacional compreende o nível administrativo da instituição de ensino superior.

\section{0 ambiente do ensino superior}

Segundo Davenport e Prussak (1998), Nonaka e Takeuchi (1997), a informação submetida a processo cognitivo de reflexão e síntese equivale-se ao conhecimento, compreendendo uma base técnica e outra cognitiva e que, sob determinados contextos, converte-se em inteligência. $\mathrm{O}$ valor do conhecimento pode assegurar competência às pessoas e competitividade às organizações e, assim, adicionar valor à atividade humana e corporativa.

O conhecimento, uma das dimensões da competência, conforme preconizado por Durand (1998), apresenta-se enraizado no meio acadêmico. A construção do conhecimento acadêmico é, sobretudo, base para o desenvolvimento tanto do profissional quanto do cidadão. A educação encaminha para adoção de uma nova pedagogia fundamentada no processo científico, na unidade e na universalidade, remetendo à renovação do homem, dos programas, das instituições, o que pressupõe inovação do espírito pedagógico (DEMO, 2000). Esta abordagem de ensino superior vem ultrapassar as práticas tradicionalmente adotadas e busca tratar, equilibradamente, tanto os pressupostos da ciência e da tecnologia, quanto às necessidades do homem e da sociedade.

Considerando as mudanças tecnológicas e o cenário evolutivo da educação, Abreu, Gonçalves e Pagnozzi (2003) pontuam que as organizações buscam no processo de aprendizagem contínua uma forma de construir inteligência corporativa competitiva. Explicam ainda que, em função da estruturação organizacional, as empresas têm caminhado rumo à adoção de um modelo de educação híbrido, participando ativamente do processo de ensino-aprendizagem e compartilhando responsabilidades com instituições de ensino, atividade anteriormente exclusiva da academia.

O processo de globalização e as tecnologias de informação e comunicação têm impelido as instituições educacionais a uma redefinição do seu papel. Em nível de educação superior, estes condicionantes determinam a adoção de modelo includente, em detrimento de 
um modelo concentrador, pelas universidades, centros universitários, faculdades e institutos ou escolas superiores (FORGRAD, 2002).

$\mathrm{Na}$ perspectiva includente, concebe-se educação superior como uma instituição social que apresenta como propósito à formação intelectual e científica da sociedade em que está inserida. A instituição social caracteriza-se por apresentar estabilidade e durabilidade de sua missão e repousa sua estrutura em normas e valores do grupo ou sociedade em que se insere (COLOSSI, CONSENTINO e QUEIROZ, 2001).

No Brasil, o aumento da demanda pelo ensino superior propiciou oportunidade de ingresso de instituições de ensino privado. Com o processo de abertura do mercado e dos dispositivos legais, houve um crescimento na participação de instituições privadas, ampliando o número de vagas e, conseqüentemente, gerando maior necessidade de controle em função da delegação das atividades por parte do governo às instituições privadas.

\section{0 ensino superior privado no contexto nacional}

O ensino superior privado brasileiro esteve focado, em passado recente, na oferta de cursos de formação plena. Os cursos de graduação, em específico, apresentavam um currículo extenso, às vezes com sobreposição de conteúdo para justificar a extensão da carga horária, enquanto se acenava para a adequação dos currículos às necessidades do mercado, como por exemplo, cursos com carga horária reduzida e que atendessem problemas emergentes. $\mathrm{O}$ fato é que esta defasagem passa a demandar o monitoramento da regulamentação do ensino e dos anseios do mercado de trabalho.

Em face de novos entrantes no mercado e do aumento da oferta de vagas, as instituições de ensino foram forçadas a conviver com o acirramento da concorrência. Com isso aumentaram a necessidade de desenvolver meios para identificar os atores e suas forças a fim de implementar estratégias que permitissem melhorar o posicionamento competitivo.

Consoante às tendências do mercado profissional, a educação brasileira passa por mudanças decorrentes da aplicação de dispositivos legais, com ênfase para a delegação parcial das atribuições governamentais à iniciativa privada (CONSTITUIÇÃO FEDERAL, 1988). Nessa perspectiva, a educação em nível superior passa a se ancorar em investimentos de iniciativa privada, responsável por oitenta por centro das vagas oferecidas.

A partir daí, de acordo com Santos (1999), as instituições educacionais envolvidas num contínuo processo de inovação, fundamentam suas políticas em princípios: a) cidadania como patrimônio universal; b) autonomia universitária; c) ética na atividade humana; d) 
responsabilidade institucional e social; e) nova visão de futuro; f) relação com a sociedade e o mundo do trabalho; g) empreendedorismo; h) excelência no ensino.

Nas raízes da expansão do ensino superior, observa-se a predominância dos critérios de busca de atendimento de necessidades voltadas para o mercado com predominância dos interesses econômicos. Isto pode trazer risco de mercantilização do ensino superior, em detrimento das ações que privilegiem os aspectos sociais e o atendimento de minorias (COLOSSI, CONSENTINO e QUEIROZ, 2001).

A nova legislação aponta para a conciliação entre os aspectos econômico e social, incitando as instituições de ensino superior para: a) incorporação de metodologias inovadoras e ativas; b) articulação da subjetividade com a objetividade; c) criação de ambiente favorável ao exercício das atividades acadêmicas; d) indissociação do ensino-pesquisa-extensão; e) integração curricular; f) interdisciplinaridade; g) aceleração da educação (VEIGA, 2000).

Os princípios e valores norteadores do novo modelo educacional convergem para a profissionalização de operações. Por sua vez, provocam o desenvolvimento de modelos de gestão capazes de reconhecer vantagens competitivas e de desafiar a competitividade institucional, por considerar que o ambiente apresenta-se de forma recessiva em função da diminuição do poder de compra de seus clientes.

\section{Indicadores para monitoramento de um sistema de inteligência competitiva em instituições de ensino superior}

A instituição na qual se realizou a pesquisa desenvolve atividades de ensino superior no Triângulo Mineiro há mais de meio século, e foi elevada ao status de Universidade em 1989, denominada Universidade de Uberaba (UNIUBE). É mantida por uma sociedade educacional privada e sem fins lucrativos, e oferece trinta e cinco cursos de ensino superior e treze em nível de pós-graduação lato sensu e um em nível de stricto sensu. Atualmente possui aproximadamente 8500 estudantes, distribuídos em dois campus universitários.

A Universidade de Uberaba está configurada sob uma estrutura matricial, que apresenta uma assessoria e um comitê de marketing como responsáveis pelo monitoramento dos concorrentes e relacionamento com clientes. O sistema de inteligência competitiva, é uma atividade ainda elementar, que não adota métodos e ferramentas de Inteligência Competitiva como forma inovadora de vigilância e prospecção mercadológica.

A proposta de matriz para monitorar o sistema de inteligência competitiva é composta por um conjunto de indicadores que foi denominado Matriz de Inteligência Competitiva para Instituição de Ensino Superior, resultado da reflexão teórica e da comparação com os modelos Revista Produção Online, Florianópolis, v.7, n.7,p.48, dez./abr., 2007 
apresentados por Sveiby (1998), Edvinsson e Malone (1998), e Stewart (1997) para monitorar variáveis relacionadas ao capital humano, capital estrutural e capital de clientes.

A proposta prevê indicadores que ajudam a identificar a gestão acadêmica nos níveis estratégico, pedagógico e administrativo. Para cada um desses níveis a matriz propõe um conjunto de indicadores para monitorar os clientes, concorrentes fornecedores e órgãos reguladores. A matriz procura ilustrar os três níveis de gestão de uma instituição de ensino superior para evidenciar a necessidade da compatibilização das ações delineadas para cada um dos componentes propostos. Ressalta-se que um sistema de inteligência competitiva aplicado a instituições de ensino superior concebe a instituição como unidade de negócio, de forma que o rastreamento das tendências e do desenvolvimento de bens e serviços são variáveis interdependentes, que sinergicamente contribuem para os objetivos organizacionais.

A matriz de indicadores para o nível estratégico refere-se aos aspectos institucionais de longo prazo. Segundo Tachizawa e Scaico (1997), a essência da formulação de estratégias corporativas busca relacionar uma empresa ao seu meio ambiente, para identificar os elementos estratégicos genéricos. Por considerar que o sistema de inteligência competitiva traz em seu bojo o conceito de componente estratégico, caracterizado como um evento, descontinuidade ou tendência, no ambiente externo da instituição pode afetar significativamente as atividades da organização. Costa (2002) explica que componentes estratégicos podem colocar em risco o crescimento ou a sobrevivência da organização, por tal motivo, merecem monitoramento contínuo.

No nível pedagógico contemplam-se indicadores quanto ao desenvolvimento da estrutura organizacional, do sistema de informação e dos recursos humanos como meios para monitorar se as ações pedagógicas convergem para os objetivos estratégicos e administrativos da instituição de ensino superior. Os indicadores propõem analisar as inovações do espaço acadêmico, onde as ações educacionais devem voltar-se para a formação de um profissional que tenha a participação ativa na construção de seu aprendizado e que esteja preparado para responder às necessidades decorrentes das mudanças da sociedade contemporânea.

O nível administrativo representa o conjunto de sistemas administrativos, conceitos organizacionais, modelos, rotinas, marcas, imagens da empresa, patentes, softwares, invenções, banco de dados, publicações, enfim, toda infra-estrutura necessária para prover o funcionamento de uma organização. Apresenta como características o maior grau de detalhamento e especificidade, natureza analítica, foco no curto prazo, microorientação para tarefas e cargos.

Para monitorar o nível estratégico, a matriz de inteligência competitiva propõe que o Revista Produção Online, Florianópolis, v.7, n.7,p.49, dez./abr., 2007 
componente cliente acompanhe o índice de satisfação de clientes, trancamento de matrículas, evasão, clientes que voltam à instituição para fazer novos cursos, além do acompanhamento dos egressos. O componente concorrente deve ater-se ao acompanhamento do número de concorrentes e o número de clientes dos três principais concorrentes. Com relação ao componente fornecedor, este se preocupa com as metas atingidas pelos coordenadores de área, tempo de dedicação às atividades estratégicas dos coordenadores, capacitação dos coordenadores, além das alianças estratégicas firmadas com outras instituições. $\mathrm{O}$ componente órgãos reguladores, acompanha o conceito dos estudantes no Exame Nacional de Curso, as exigências atendidas no processo de avaliação institucional, a média de estudantes por turma e por docente, de inscritos nos processos seletivos, bem como os ingressantes em relação aos inscritos totais nos processos seletivos.

No monitoramento do nível pedagógico, o componente cliente prevê analisar o percentual de clientes envolvidos em atividades extracurriculares, o percentual de trancamento de matrícula, o índice de aprovação dos clientes, a satisfação quanto ao projeto pedagógico e a retenção dos clientes. Importa ao componente concorrente acompanhar os novos cursos ofertados, eventos ocorridos no ano, as publicações anuais e o número de núcleos de pesquisa. Quanto ao componente fornecedor, este busca acompanhar o investimento na qualificação do corpo docente, a satisfação dos docentes e seu regime de trabalho, além do tempo dos coordenadores dedicado à pesquisa e extensão. Cabe aos órgãos reguladores verificar a evolução dos conceitos conferidos aos cursos pelo Mistério da Educação e Cultura (MEC), número de cursos recomendados pela Coordenação de Aperfeiçoamento de Pessoal de Nível Superior (CAPES) e projetos de iniciação científica.

O nível administrativo, quando relacionado ao componente cliente, preocupa-se com o índice de inadimplência, a ocupação das salas, a satisfação dos clientes quanto à infraestrutura, ao suporte técnico, à adequação da biblioteca, número de bolsas parciais e integrais cedidas por curso e a lucratividade por cliente. No que se refere ao componente concorrente cabe acompanhar a evolução das mensalidades, os descontos praticados e o número de bolsas integrais e parciais dos cursos concorrentes. $\mathrm{O}$ componente fornecedor observa a satisfação dos técnicos-administrativos, a qualificação dos funcionários, o tempo médio de profissão dos docentes, técnico-administrativo, a rotatividade dos funcionários e o número de estudantes por técnico-administrativo. O componente órgãos reguladores analisa a política de aquisição e renovação do acervo bibliográfico, a adequação das instalações aos portadores de necessidades especiais, plano de cargos e salários, execução do planejamento estratégico e da avaliação institucional.

Revista Produção Online, Florianópolis, v.7, n.7,p.50, dez./abr., 2007 
A conjunção dos indicadores propostos forma a Matriz de Inteligência Competitiva para Instituição de Ensino Superior, como demonstrada no Quadro 1.

\begin{tabular}{|c|c|c|}
\hline ESTRATÉGICO & PEDAGÓGICO & ADMINISTRATIVO \\
\hline Cliente & $\begin{array}{c}\text { Cliente } \\
\end{array}$ & Cliente \\
\hline Índice de clientes satisfeitos & $\begin{array}{l}\text { Percentual de clientes envolvidos em } \\
\text { atividades extracurriculares }\end{array}$ & Índice de inadimplência \\
\hline Índice de trancamento de matrículas & $\begin{array}{l}\text { Percentual de trancamento de } \\
\text { matrícula }\end{array}$ & Índice de ocupação de salas \\
\hline Índice de evasão & Índice de aprovação dos clientes & $\begin{array}{l}\text { Índice de satisfação dos clientes } \\
\text { quanto à infra-estrutura }\end{array}$ \\
\hline $\begin{array}{l}\text { Índice de clientes que voltam para } \\
\text { novos cursos }\end{array}$ & $\begin{array}{l}\text { Índice de satisfação dos clientes } \\
\text { quanto a projeto pedagógico }\end{array}$ & $\begin{array}{l}\text { Índice de satisfação dos clientes } \\
\text { quanto ao suporte técnico }\end{array}$ \\
\hline $\begin{array}{l}\text { Número de contatos com os egressos } \\
\text { no ano }\end{array}$ & Índice de retenção dos clientes & Número de bolsas integrais por curso \\
\hline & & Número de bolsas parciais por curso \\
\hline & & Lucratividade por cliente \\
\hline Concorrente & Concorrente & $\begin{array}{r}\text { Concorrente } \\
\end{array}$ \\
\hline Número de concorrentes & Número de novos cursos ofertados & $\begin{array}{l}\text { Valor da mensalidade dos três } \\
\text { principais concorrentes }\end{array}$ \\
\hline Número de clientes dos concorrentes & Número de eventos no ano & $\begin{array}{l}\text { Descontos praticados pelos três } \\
\text { principais concorrentes }\end{array}$ \\
\hline & Número de núcleos de pesquisas & Número de bolsas integrais por curso \\
\hline & Número de publicações anual & Número de bolsas parciais por curso \\
\hline Fornecedor & Fornecedor & Fornecedor \\
\hline $\begin{array}{l}\text { Percentual de Coordenadores de áreas } \\
\text { que atinge as metas estabelecidas }\end{array}$ & $\begin{array}{l}\text { Percentual do faturamento investido } \\
\text { na qualificação do corpo docente }\end{array}$ & $\begin{array}{l}\text { Grau de satisfação dos técnicos } \\
\text { administrativos }\end{array}$ \\
\hline $\begin{array}{lll}\text { Percentual do tempo dos } & \text { do } \\
\text { Coordenadores } & \text { dedicado à atividade } \\
\text { estratégica } & & \end{array}$ & Grau de satisfação dos docentes & Índice de funcionários qualificados \\
\hline $\begin{array}{l}\text { Percentual de parceiros estratégicos } \\
\text { em relação ao número de parceiros } \\
\text { total }\end{array}$ & Índice de qualificação docente & Tempo médio de profissão docentes \\
\hline $\begin{array}{l}\text { Percentual do faturamento total em } \\
\text { capacitação dos colaboradores }\end{array}$ & $\begin{array}{l}\text { Percentual dos docentes em regime } \\
\text { integral }\end{array}$ & Rotatividade anual de funcionários \\
\hline $\begin{array}{l}\text { Percentual de coordenadores com } \\
\text { formação em gestão acadêmica }\end{array}$ & $\begin{array}{l}\text { Percentual do tempo dos } \\
\text { Coordenadores dedicado à pesquisa e } \\
\text { extensão }\end{array}$ & $\begin{array}{l}\text { Tempo médio de profissão técnico } \\
\text { administrativo }\end{array}$ \\
\hline & & $\begin{array}{l}\text { Número de estudantes por técnicos } \\
\text { administrativos }\end{array}$ \\
\hline Órgãos reguladores & Órgãos reguladores & \begin{tabular}{|l} 
Órgãos reguladores \\
\end{tabular} \\
\hline $\begin{array}{l}\text { Percentual de estudantes com conceito } \\
\text { superior a média do exame nacional de } \\
\text { cursos }\end{array}$ & $\begin{array}{l}\text { Evolução dos conceitos conferidos } \\
\text { pelo MEC aos cursos (A/B/C/D) }\end{array}$ & $\begin{array}{l}\text { Periodicidade de aquisição e } \\
\text { renovação do acervo }\end{array}$ \\
\hline $\begin{array}{l}\text { Percentual de exigências atendidas no } \\
\text { processo de Avaliação Institucional }\end{array}$ & $\begin{array}{l}\text { Número de cursos recomendados pela } \\
\text { CAPES }\end{array}$ & \begin{tabular}{|lccr} 
Percentual de adequação & das \\
instalações aos portadores & de \\
necessidades especiais & \\
\end{tabular} \\
\hline $\begin{array}{l}\text { Número médio de estudantes por } \\
\text { turma }\end{array}$ & \begin{tabular}{|lll}
$\begin{array}{l}\text { Número de projetos de iniciação } \\
\text { científica }\end{array}$ & \\
\end{tabular} & $\begin{array}{l}\text { Número médio de empréstimos do } \\
\text { acervo bibliográfico }\end{array}$ \\
\hline Número de estudantes por docente & & 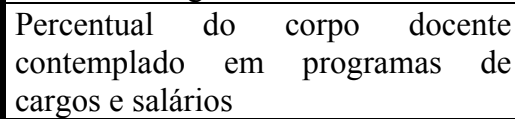 \\
\hline $\begin{array}{l}\text { Número de candidatos inscritos nos } \\
\text { processos seletivos }\end{array}$ & & $\begin{array}{l}\begin{array}{l}\text { Percentual de execução } \\
\text { planejamento estratégico }\end{array} \\
\text { do }\end{array}$ \\
\hline $\begin{array}{l}\text { Percentual de ingressantes em relação } \\
\text { aos inscritos nos processos seletivos }\end{array}$ & & $\begin{array}{l}\text { Percentual de execução da avaliação } \\
\text { institucional }\end{array}$ \\
\hline
\end{tabular}

Quadro 1 - Matriz de Inteligência Competitiva (IC) para Instituição de Ensino Superior 
Para operacionalização da proposta de indicadores para um sistema de inteligência competitiva em instituição de ensino superior, no nível estratégico, a organização estudada apresenta os elementos apresentados no Quadro 2.

\begin{tabular}{|c|c|c|}
\hline \multicolumn{3}{|c|}{ NÍVEL ESTRATÉGICO } \\
\hline $\begin{array}{l}\text { Apresenta infra-estrutura e } \\
\text { realiza atividade }\end{array}$ & $\begin{array}{l}\text { Apresenta infra-estrutura e não } \\
\text { realiza atividade }\end{array}$ & Não apresenta infra-estrutura \\
\hline $\begin{array}{lcr}\text { Pró-Reitorias } & \text { para } & \text { celebrar } \\
\text { convênios } & \text { com } & \text { outras } \\
\text { instituições } & \text { em } & \text { atividades } \\
\text { curriculares e extracurriculares }\end{array}$ & $\begin{array}{l}\text { Departamento de marketing para } \\
\text { pesquisa de satisfação }\end{array}$ & $\begin{array}{l}\text { Sistema de gestão integrado de } \\
\text { matrícula e evasão }\end{array}$ \\
\hline $\begin{array}{l}\text { Banco de dados para elaboração } \\
\text { do catálogo institucional e } \\
\text { avaliação institucional, do } \\
\text { Exame Nacional de Cursos, } \\
\text { processo de (re) credenciamento } \\
\text { e reconhecimento de curso. }\end{array}$ & $\begin{array}{l}\text { Departamento de marketing para } \\
\text { monitorar concorrente }\end{array}$ & $\begin{array}{l}\text { Comissão de execução e avaliação } \\
\text { do planejamento estratégico } \\
\text { institucional }\end{array}$ \\
\hline $\begin{array}{l}\text { Acesso a outros bancos de dados } \\
\text { para elaboração do catálogo } \\
\text { institucional e avaliação } \\
\text { institucional, do Exame } \\
\text { Nacional de Cursos, processo de } \\
\text { (re) credenciamento e e } \\
\text { reconhecimento de curso. }\end{array}$ & $\begin{array}{lcc}\begin{array}{l}\text { Departamento } \\
\text { acadêmico }\end{array} & \text { de } & \begin{array}{l}\text { controle } \\
\text { para }\end{array} \\
\text { fornecer } \\
\text { informações de } \\
\text { coordenadores }\end{array}$ & \\
\hline \multirow[t]{2}{*}{$\begin{array}{l}\text { Sistema acadêmico de alunos } \\
\text { por turma, docente e } \\
\text { ingressantes por processo } \\
\text { seletivo. }\end{array}$} & $\begin{array}{lrr}\text { Departamento financeiro } & \text { para } \\
\text { controlar investimentos } & \text { em } \\
\text { capacitação de colaboradores } & \end{array}$ & \\
\hline & $\begin{array}{l}\text { Departamento de Recurso Humanos } \\
\text { para controle do perfil de } \\
\text { competência no recrutamento, } \\
\text { seleção e promoção de } \\
\text { coordenadores, docentes e técnicos. }\end{array}$ & \\
\hline
\end{tabular}

Quadro 2 - Elementos facilitadores para consecução de atividade de IC no nível estratégico

Quanto aos recursos pesquisados para operacionalização da proposta, a organização apresenta os elementos elencados no Quadro 3 para monitorar o nível pedagógico. 


\begin{tabular}{|c|c|c|}
\hline \multicolumn{3}{|c|}{ NÍVEL PEDAGÓGICO } \\
\hline $\begin{array}{l}\text { Apresenta infra-estrutura e } \\
\text { realiza atividade }\end{array}$ & $\begin{array}{l}\text { Apresenta infra-estrutura e não } \\
\text { realiza atividade }\end{array}$ & Não apresenta infra-estrutura \\
\hline $\begin{array}{l}\text { Departamento de controle } \\
\text { acadêmico para acompanhar } \\
\text { atividades extracurriculares, } \\
\text { índice de aprovação, } \\
\text { trancamento de matrículas e } \\
\text { retenção de clientes. }\end{array}$ & $\begin{array}{l}\text { Coordenação pedagógica para } \\
\text { pesquisa de satisfação quanto ao } \\
\text { projeto pedagógico }\end{array}$ & $\begin{array}{l}\text { Departamentos para acompanhar } \\
\text { políticas de investimento e } \\
\text { capacitação docente }\end{array}$ \\
\hline 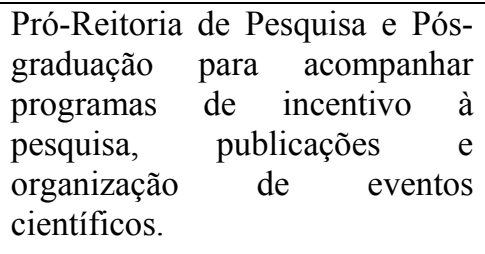 & & $\begin{array}{l}\text { Comissão para pesquisa de } \\
\text { satisfação dos docentes }\end{array}$ \\
\hline $\begin{array}{l}\text { Órgão de planejamento } \\
\text { acadêmico para acompanhar os } \\
\text { docentes em regime de trabalho } \\
\text { e carga horária de pesquisa }\end{array}$ & & \\
\hline $\begin{array}{lr}\text { Pró-Reitorias } & \text { para } \\
\text { acompanhamento de conceitos } \\
\text { de cursos de ensino superior e } \\
\text { pós-graduação. }\end{array}$ & & \\
\hline
\end{tabular}

Quadro 3 - Elementos facilitadores para consecução de atividade de IC no nível pedagógico

No que diz respeito aos recursos necessários para operacionalizar a proposta de indicadores na instituição de ensino superior, no nível administrativo foram observados os elementos evidenciados no Quadro 4.

\begin{tabular}{|c|c|c|}
\hline \multicolumn{3}{|c|}{ NÍVEL ADMINISTRATIVO } \\
\hline $\begin{array}{l}\text { Apresenta infra-estrutura e } \\
\text { realiza atividade }\end{array}$ & $\begin{array}{c}\text { Apresenta infra-estrutura e não } \\
\text { realiza atividade }\end{array}$ & Não apresenta infra-estrutura \\
\hline $\begin{array}{l}\text { Departamento financeiro para } \\
\text { acompanhar inadimplência } \mathrm{e} \\
\text { lucratividade dos clientes }\end{array}$ & $\begin{array}{lcr}\text { Diretoria } & \text { de } & \text { Programação e } \\
\text { Pesquisa } & \text { para } & \text { acompanhar } \\
\text { adequação } & \text { das instalações aos } \\
\text { portadores } & \text { de } & \text { necessidades } \\
\text { especiais } & & \end{array}$ & $\begin{array}{l}\text { Departamento financeiro para } \\
\text { acompanhar concessão de bolsas } \\
\text { de estudo do concorrente }\end{array}$ \\
\hline \multirow[t]{3}{*}{$\begin{array}{l}\text { Diretoria de programação e } \\
\text { pesquisa para acompanhar a } \\
\text { ocupação de sala de aula, } \\
\text { biblioteca e laboratórios. }\end{array}$} & $\begin{array}{l}\text { Comissão } \quad \mathrm{de} \\
\text { institucional }\end{array}$ & $\begin{array}{l}\text { Departamento } \text { de recursos } \\
\text { humanos para pesquisa de } \\
\text { satisfação dos } \\
\text { administrativos }\end{array}$ \\
\hline & & $\begin{array}{l}\text { Departamento } \text { de recursos } \\
\text { humanos para controle do tempo } \\
\text { de profissão, rotatividade de } \\
\text { docentes e de técnico- } \\
\text { administrativos. }\end{array}$ \\
\hline & & $\begin{array}{l}\text { Comissão de execução do } \\
\text { planejamento estratégico }\end{array}$ \\
\hline
\end{tabular}

Quadro 4 - Elementos facilitadores para consecução de atividade de IC no nível administrativo 
A matriz de inteligência competitiva para instituição de ensino superior configura-se com um formato de apresentação dos indicadores relevantes, que auxiliam na avaliação de itens tangíveis e intangíveis das instituições de ensino superior. De acordo com Costa (2002), a lista dos componentes deve ser continuamente cotejada e monitorada para incluir novos tópicos ou eliminar aqueles itens que se apresentam como alarmes falsos, gerando apenas desconfianças ou preocupações infundadas.

Ressalta-se que a existência de várias medidas não-financeiras, possíveis de serem adaptadas à matriz proposta, pode levar a organização a utilizar um número excessivo de índices, dificultando o acompanhamento periódico dos indicadores. Assim, a escolha dos indicadores depende da estratégia da instituição, os quais podem ser utilizados, sobretudo, para o acompanhamento de uma estratégia orientada para o conhecimento.

\section{Considerações finais}

A matriz de inteligência competitiva para instituição de ensino superior não objetiva contemplar um quadro completo dos indicadores pesquisados e tidos como aplicáveis às instituições de ensino. Um sistema de avaliação com essa amplitude parece ser impossível estratégica, metodológica e financeiramente.

A inteligência competitiva está vinculada à administração, utilização e disseminação da informação para atingir os objetivos estratégicos e táticos da organização. Sua essência consiste nas sucessivas transposições de conhecimentos tácitos em explícitos. Consubstanciase como processo que busca acumular o conhecimento estratégico, a partir da coleta, tratamento e disseminação de informações sobre os concorrentes, mercado, clientes, fornecedores, enfim do ambiente externo competitivo em geral.

A partir da matriz de inteligência competitiva para instituições de ensino superior, acredita-se ser possível acompanhar as ações empregadas nas instituições de ensino nos níveis estratégico, pedagógico e administrativo, sob a ótica do cliente, concorrente, fornecedores e órgãos reguladores. Embora a proposta não contemple todos os indicadores possíveis para se avaliar a infra-estrutura de uma instituição de ensino superior, pois um sistema desse porte parece ser exaustivo e comprometedor da relação custo-benefício da informação.

O estudo apresenta sugestões iniciais, a partir das quais, cada instituição pode criar indicadores próprios de acordo com as necessidades e possibilidades de se acompanhar e comparar ao longo do tempo. Por isso, deve ser vista na perspectiva de sugestões, a partir das 
quais as instituições possam adaptar os indicadores de acordo com suas necessidades e particularidades do segmento em que atuam.

À medida que as organizações interagem em seus ambientes, elas absorvem informações, transformam-nas em conhecimento e agem com base nessa combinação de conhecimentos, experiências, valores e regras internas, buscando identificar as informações como uma ferramenta decisiva para alavancar o sucesso organizacional e criar diferenciais competitivos que sustentem sua permanência no mercado competidor. Assim, com o monitoramento das ações e estratégias, pedagógicas e administrativas, pode agregar maior valor à estrutura interna da instituição e, conseqüentemente, aos clientes, que esperam por excelência no atendimento.

\section{Referências}

ABREU, Aline França; GONÇALVES, Caio Márcio; PAGNOZZI, Leila. Tecnologia da informação e educação corporativa: contribuições e desafios da modalidade de ensinoaprendizagem à distância no desenvolvimento de pessoas. Revista PEC Programa de Educação Corporativa. Curitiba, n 1, v.3, p.47-58, jan./ dez. 2003.

ANDRADE, Maria Margarida. Como preparar trabalhos para cursos de pós-graduação: noções práticas. 5. ed. São Paulo: Atlas, 2002.

AYRES, Fernando Arduini; et al. Base conceitual e prática para implementação de um sistema de inteligência competitiva em uma universidade particular. In: Workshop Brasileiro de Inteligência Competitiva e Gestão do Conhecimento, I, 1999. Rio de Janeiro. Anais... Rio de Janeiro-RJ: FINEP, 1999. CD-ROM.

BAÊTA, Adelaide Maria Coelho; MARTINS, Ângela Melo; BAÊTA, Flávia Maria Coelho. Gestão do conhecimento para o processo de inovação: o caso de uma empresa brasileira. In: ENANPAD, XXVI, 2002. Salvador. Anais... Salvador-BA: ANPAD, 2002. CD-ROM.

BRASIL. Constituição da república federativa do Brasil: promulgada em 5 de outubro de 1988. Organização do texto: Juarez de Oliveira. 4. ed. São Paulo: Saraiva, 1990.

CERVO, Amado Luiz; BERVIAN, Alcino. Metodologia científica: para uso dos estudantes universitários. 3. ed. São Paulo: McGraw-Hill do Brasil, 1983.

CHOO, C.W., Information management for intelligent organization: the art of scanning the environment. New Jersey: Asis Monograph Series, 1998.

COLAUTO, Romualdo Douglas et al. Os fatores críticos de sucesso como suporte ao sistema de inteligência competitiva: o caso de uma empresa brasileira. In: CONGRESSO LATINO AMERICANO DE ESTRATÉGIA, XVII, 2004. Itapema. Anais... Itapema-SC: UNIVALE, 2004, CD-ROM.

COLOSSI, Nelson; CONSENTINO, Aldo; QUEIROZ, Etty Guerra de. Mudanças no contexto do ensino superior no Brasil: uma tendência ao ensino colaborativo. Revista FAE Business

School. v. 4. n.1, p.49-58, jan./ abr. 2001.

COSTA, Eliezer Arantes da. Gestão estratégica. São Paulo: Saraiva, 2002.

DAVENPORT, T.H. Ecologia da informação. São Paulo: Futura,1998. 
DAVENPORT, Thomas H.; PRUSAK, L. Conhecimento empresarial: como as organizações gerenciam o seu capital intelectual. Rio de Janeiro: Campus, 1998.

DEMO, Pedro. Educar pela pesquisa. 4. ed. São Paulo: Autores Associados, 2000.

DURAND, T. Forms of incompetence. In: International Conference on Competence Based Management, IV, 1998. Oslo. Anais... Oslo. NORWEGIAN SCHOOL MANAGEMENT, 1998, CD-ROM.

EDVINSSON, Leif; MALONE, Michael S. Capital intelectual: descobrindo o valor real de sua empresa pela identificação de seus valores internos. São Paulo: Makron Books, 1998.

FORGRAD, Fórum de Pró-Reitores de Graduação das Universidades Brasileiras. Resgatando espaços e construindo idéias de 1997 a 2002. Niterói: Editora da UFF, 2002.

FULD, Leonard. Administrando a concorrência. Rio de Janeiro: Record, 1995.

GOMES, Elisabeth; BRAGA, Fabiane. Inteligência competitiva: como transformar informação em um negócio lucrativo. Rio de Janeiro: Campus, 2001.

HERING, J. P. What is intelligence analysis? Competitive Intelligence Magazine. v.1, n.2, Jul./ Aug. p.13-16, 1997.

KAHANER, Larry. Competitive Intelligence: how to gather, analyze, and use information to move your business to the top. New York: Touchstone Books, 1998.

LAUDON, K.C.; LAUDON, J.P. Gerenciamento de sistemas de informação. Rio de Janeiro: LTC, 2001.

MARCONI. Marina de Andrade; LAKATOS, Eva Maria. Técnicas de pesquisa. 5. ed. São Paulo: Atlas, 2002.

MORESI, E. A. D. Gestão da informação e do conhecimento. In: TARAPANOFF, K. (Org.). Inteligência organizacional e competitiva. Brasília: Editora UNB, 2001, p.111-142.

NONAKA, Ikujiro; TAKEUCHI, Hirotaka. Criação do conhecimento na empresa: como as empresas japonesas geram a dinâmica da inovação. Rio de Janeiro: Campus, 1997.

POPPER, Karl. A lógica da pesquisa científica. 2. ed. São Paulo: Cultrix, 1972.

POZZEBON, Marlei; FREITAS, Henrique M.R. de; PETRINI, Maira. Pela integração da inteligência competitiva nos Enterprise Information Systems (EIS). Ciência da informação. Brasília, v.23, n.3, p.35,1997.

RAUPP, Fabiano Maury; BEUREN, Ilse Maria. Metodologia da pesquisa aplicável às ciências sociais. In: BEUREN, Ilse Maria (Coord.) Como elaborar trabalhos monográficos em contabilidade: teoria e prática. São Paulo: Atlas, 2003, p.76-97.

REZENDE, Denis Alcides; ABREU, Aline França de. Tecnologia da informação aplicada a sistemas de informação empresariais: o papel estratégico da informação e dos sistemas de informação nas empresas. São Paulo: Atlas, 2000.

RICHARDSON, Roberto Jarry. Pesquisa social: métodos e técnicas. 3. ed. São Paulo: Atlas, 1999.

SANTOS, Márcia M. C. (Org.). Projeto pedagógico: subsídios para elaboração e avaliação. Caxias do Sul: EDUCS, 1999.

STEWART, Thomas A. Capital intelectual: a nova vantagem competitiva das empresas. 7. ed. Rio Janeiro: Campus, 1997. 
SVEIBY, Karl E. A nova riqueza das organizações: gerenciando e avaliando patrimônios do conhecimento. 4. ed. Rio de Janeiro: Campus, 1998.

TACHIZAWA, Takeshy; SCAICO, Oswaldo. Organização flexível: qualidade na gestão por processos. São Paulo: Atlas, 1997.

TARAPANOFF, Kira. (Org.). Inteligência organizacional e competitiva. Brasília: Editora UNB, 2001. p.303-326.

TEIXEIRA FILHO, Jayme. Gerenciando conhecimento. Rio de Janeiro: Senac, 2000.

TRIPODI, T; FELLIN, P.; MAYER, H. Análise da pesquisa social. Rio de Janeiro: Francisco Alves, 1981.

TRIVIÑOS, Augusto N. S. Introdução à pesquisa em ciências sociais: a pesquisa qualitativa em educação. São Paulo: Atlas, 1987.

TYSON, Kirk W. M. Guide to competitive intelligence: gathering, analysing, and using competitive intelligence. Chicago: Kirk Tyson, 1998.

UENO, A. T. Concepção de um sistema de inteligência competitiva de clusters empresariais orientado para economia digital. In: Workshop Brasileiro de Inteligência Competitiva e Gestão do Conhecimento, I, 2001. Florianópolis. Anais... Florianópolis-SC: FIESC, 2001. CD-ROM.

VEIGA, Ilma P. A. Projeto político-pedagógico: continuidade ou transgressão para acertar? In: CASTANHO, Sérgio; CASTANHO, Maria Eugênia L.M. (Orgs.) O que há de novo na educação superior: do projeto pedagógico à prática transformadora. Campinas: Papirus, 2000, p.40-68. 